\title{
脳動脈瘤手術による穿通枝障害
}

\author{
牛越 聡，藤原 浩章，三平 剛志 \\ 曲沢＼cjkstart聡，鈴木 明文，安井 信之
}

\section{Injury to Perforating Artery During Aneurysmal Surgery}

Satoshi Ushikoshi, M.D., Hiroaki Fujiwara, M.D., Takeshi Sampei, M.D.,

Satoshi Magarisawa, M.D., Akifumi Suzuki, M.D., and Nobuyuki Yasui, M.D

Department of Surgical Neurology, Research Institute for Brain and Blood Vessels-Akita, Akita, Japan

Summary: Injuries to perforating arteries are one of the most frequent complications during aneurysmal surgery. Extreme care should be taken to avoid them. Out of 366 cases that underwent radical surgery for cerebral aneurysms, 33 were reviewed that had circulatory impairment of perforating artery (confirmed by CT scan). Of the 33 cases, 18 were internal carotid artery (the incidence was $14.2 \%), 2$ middle cerebral artery (1.3\%), 2 horizontal portion of anterior cerebral artery (40\%), 6 anterior communicating artery (5.3\%), and 5 basilar artery aneurysms $(9.3 \%)$.

The causes of injury to perforating artery were as follows: insufficient identification of the perforator (9 cases), improper retraction of the brain or vessels (9 cases), temporary occlusion ( 5 cases), kinking or stenosis due to the clip ( 5 cases), premature rupture ( 2 cases), and others ( 3 cases). A neurological deficit remained in $39.3 \%$ of the cases; a particularly high incidence was noted in anterior thalamoperforating artery injuries, anterior choroidal artery injuries, and recurrent artery of Heubner injuries.

In order to reduce perforator injuries, we must manipulate carefully, approach by the minimal brain retraction method, avoid using temporary clipping, and identify perforating artery sufficiently (e.g. using endoscope).

\section{はじめに}

破裂脳動脈瘤の予後不良因子の一つに，脳血管攣縮など とならんで手術操作に伴う合併症があげられる ${ }^{16)}$ 。また 未破裂動脈瘤の治療においても, 術後神経脱落症状をきた すのは手術操作に起因することが多い ${ }^{15)}$ 。そこで, 脳動 脈瘤の手術合併症の中でも最も頻度の高いものの一つであ る穿通枝障害につき, その頻度, 原因, 臨床症状, および 対策について検討し，報告する.

\section{Key words :}

- perforating artery

- cerebral aneurysm

- microsurgery

- complication

秋田県立脳血管研究センター 脳神経外科(受稿日 1992.6.22) [連絡先： 7010 秋田市千秋久保田町 6-10 秋田県立脳血管研究センター 脳神経外科 牛越 聡] 
(1.3\%), 前大脳動脈水平部 2 例 $(40 \%)$, 前交通動脈 6 例 (5.3\%), 脳底動脈 5 例 (9.3\%) であった (Table 1).

障害された穿通枝およびその原因となった手術操作は手 術前後の CT，脳血管撮影，手術所見，術中ビデオをもと に決定し，これらを主に approach 法の違いという観点か ら, 1. 内頸動脈 - 中大脳動脈 - 前大脳動脈水平部動脈瘤, 2. 前交通動脈瘤，3. 脳底動脈瘤の 3 群に分けて検討した. 穿通枝障害による後遺症は，脳血管攣縮，全身合併症と いった他の原因により予後不良となった症例を除いた 28 例において，術後 3 力月の時点で判定した.

なお，破裂動脈瘤症例では，急性期手術を原則としてい る。また，vasospasmの予防を目的とした積極的なクモ膜 下血腫除去は行っておらず，血腫除去操作に起因した穿通 枝障害例はない ${ }^{18)}$.

\section{代 表 症 例}

\section{<症例 1> 59 歳, 男性（Fig. 1)}

突然の激しい頭痛, 哣気で発症し, day 3 に当科入院と なった. CT，脳血管撮影で，左内頸動脈一後交通動脈分岐 部動脈瘤破裂によるクモ膜下出血の診断となり，同日術前 重症度 Grade 2 (H \& K) で手術を施行した. left trans sylvian approachにより, 左内頸動脈一後交通動脈分岐部よ り後方に突出する動脈瘤に Sugita No. 18 の clip をかけた が，後交通動脈近位部より分岐する穿通枝は確認できなか った．術直後より右片麻盘が出現し，CTで anterior thalamoperforating artery 域に低吸収域が認められ，脳血管 撮影でも術前に描出されていた anterior thalamoperforating artery の閉塞が確認された。 中等度の右不全片麻痺を 後遺した.

\section{<症例 2> 34 歳, 男性（Fig. 2)}

突然の頭痛，意識障害で発症し，某医搬入された。CT にてクモ膜下出血の診断となり，当科に紹介入院となった 脳血管撮影にて前交通動脈瘤が認められ，同日術前重症度 Grade 3 (H \& K ) で緊急手術を施行した。手術はbasal interhemispheric approachにより行い, 左 $\mathrm{A}_{1}-\mathrm{A}_{2}$ junction より前方に突出する動脈瘤を認めたが, premature rupture をきたし, point-suctionにて neck lippingを行うも， この際 dome と強く癒着していた左 recurrent artery of Heubner を閉塞した。術後の CT で同領域に低吸収域が 出現したが，幸い神経脱落症状は認められなかった。

\section{〈症例 3> 65 歳，女性（Fig. 3)}

頭痛を主訴に某医を受診し診察中に突然意識消失をきた し，当科に紹介搬入された。CT，脳血管撮影で破裂脳底 動脈-左上小脳動脈分岐部動脈瘤 (H \& K Grade 4)の診断
Table 1 Site of aneurysm

\begin{tabular}{ccc}
\hline $\mathrm{IC}$ & $18 / 127$ & $(14.2 \%)$ \\
$\mathrm{MC}$ & $2 / 147$ & $(1.3 \%)$ \\
$\mathrm{A}_{1}$ & $2 / 5$ & $(40.0 \%)$ \\
$\mathrm{Acom}$ & $6 / 112$ & $(5.3 \%)$ \\
$\mathrm{BA}$ & $5 / 54$ & $(9.3 \%)$ \\
Others & $0 / 18$ & $(0 \%)$ \\
\hline Total & $33 / 336$ & $(9.2 \%)$
\end{tabular}

IC: internal carotid artery, MC: middle cerebral artery, $\mathrm{A}_{1}$ : anterior cerebral artery horizontal portion, Acom: anterior communicating artery, BA: basilar artery.

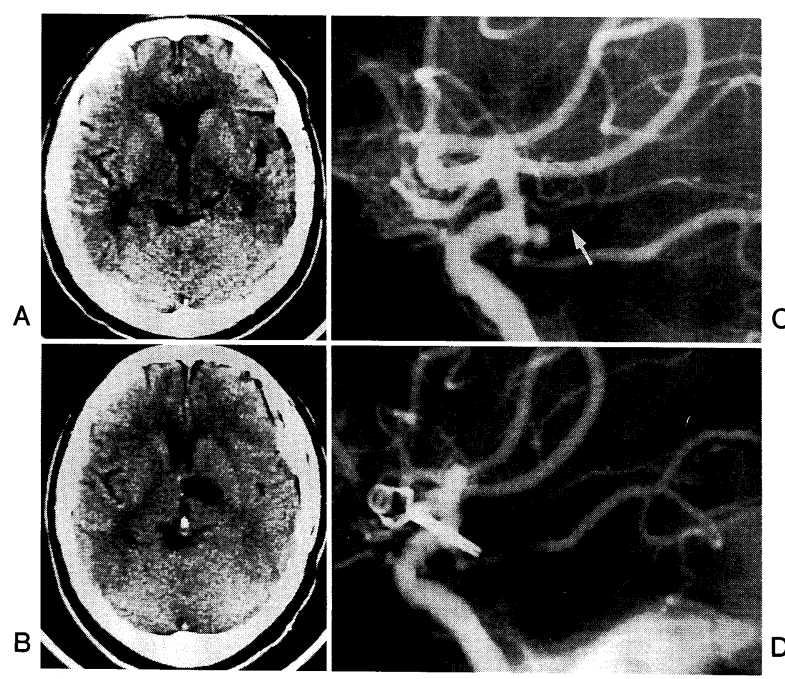

Fig. 1 Case 1. A: CT scan on admission. B: Postopera tive CT scan shows a low density area at the anterior pole of the thalamus and the anterior portion of the posterior limb of the internal capsule on the left. C, D: Pre- and postoperative left carotid angiogram (lateral view) shows a small branch arising from the posterior communicating artery (arrow) which is occluded postoperatively.

となった．意図的待機手術とし， day 17 に左 trans-sylvian approachにて手術を施行した。内頸動脈に脳べらをかけ て内側に圧排し，後交通動脈の外側より Yasargil No. 720 で neck clipping を行った. 術直後より重度右片麻舫が出 現し, CTで anterior thalamoperforating artery 領域に低 吸収が認められた.内頸動脈および後交通動脈の圧排によ る穿通枝の循環障害と考えられた。

\section{結果}

\section{1. 内頸動脈・中大脳動脈・前大脳動脈水平部動脈瘤}

これらはいずれも trans-sylvian approach にて clipping を行った。障害された穿通枝は， anterior thalamoperforating artery 7 例, anterior choroidal artery 7 例, lateral 

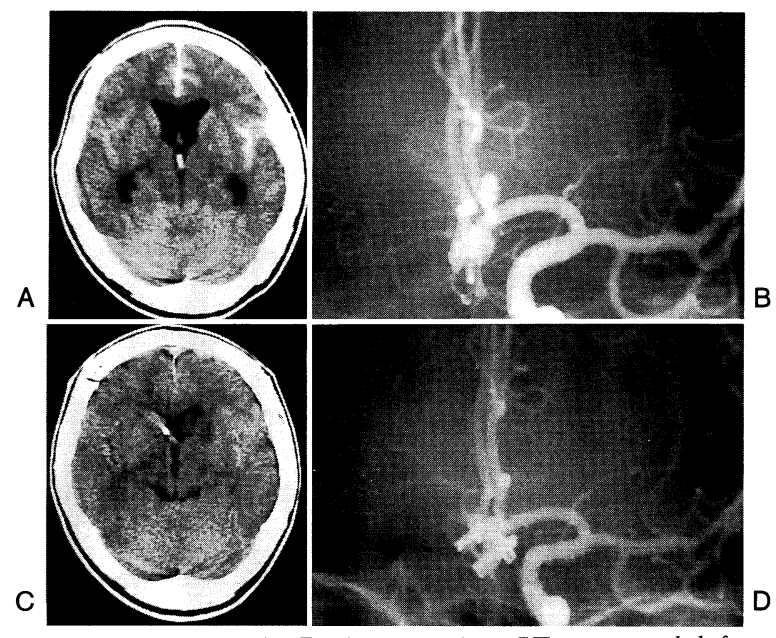

Fig. 2 Case 2. A, B: Preoperative CT scan and left carotid angiogram (anteroposterior view). C: Postoperative CT scan shows a low density area at the anterior portion of the caudate nucleus and the anterior limb of the internal capsule on the left. D: Postoperative left carotid angiogram (anteroposterior view).

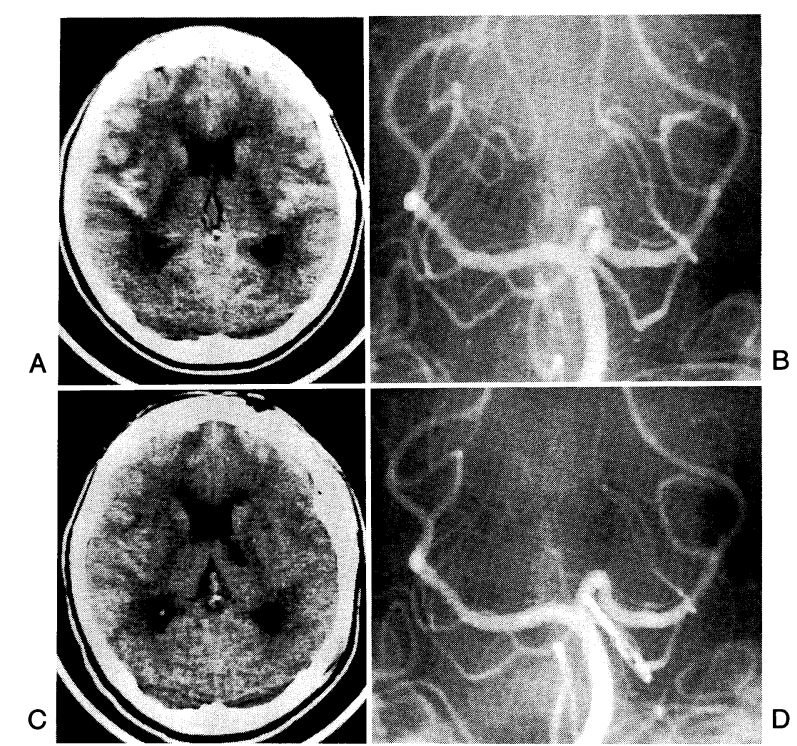

Fig. 3 Case 3. A, B: CT scan and left vertebral angiogram (anteroposterior view) on admission. C: Postoperative CT scan shows a low density area at the anterior pole of the thalamus and the most anterior portion of the posterior limb of the internal capsule on the left. D: Postoperative left vertebral angiogram (anteroposterior view). striate artery 3 例, medial striate artery 6 例であった (Table 2A). その原因としては, 穿通枝の確認が十分で きなかったものが 9 例と最も多く，その他一時血行遮断 4 例 (不適切な neck clipping により穿通枝も同時に一時的に はさんでしまったもの 3 例，母血管の temporary clipping 1 例), 過度の脳圧排により穿通枝が伸展され血流障害を 引き起こしたもの 4 例，clip による穿通枝の kink あるい は stenosis 4 例, 穿通枝が動脈瘤の domeより直接でてお り犠牲にせざるをえなかったもの 1 例であった (Table 2B).

\section{2. 前交通動脈瘤}

穿通枝障害をきたした前交通動脈瘤のうち 5 例はinterhemispheric approach にて, 多発性動脈瘤の 1 例は trans-sylvian approachにて clipping を行った. 障害され た穿通枝は recurrent artery of Heubner が 5 例 (両側障害 例 1 例)であった(Table 3). 原因としては premature rupture 2 例, temporary clipping 1 例, clip が母血管側に slip し，その穿通枝の閉塞をきたしたもの 1 例， clip による kinking 1 例であった. また, 原因は不明であるが脳梁膝 部に低吸収域の出現したものが 1 例あった。

\section{3. 脳底動脈瘤}

穿通枝障害をきたした脳底動脈瘤 5 例の内訳は, 脳底動 脈分岐部 1 例, 脳底動脈一上小脳動脈分岐部 4 例であった (Table 4).いずれも trans-sylvian approachにより，前 者は視神経と内頸動脈の間より, 後者は後交通動脈の外側 より clippingを行った。障害された穿通枝は lateral striate artery 1 例, anterior thalamoperforating artery 4 例で あった.これらはいずれも clipping 操作とは直接関係の ない部位の穿通枝であり, 脳あるいは血管の圧排による循 環障害が原因と考えられた。

\section{4. 神経脱落症状}

術後 3 力月の時点でなんらかの神経脱落症状が認められ た症例は 11 例 $(39.3 \%)$ で, これは全動脈瘤手術症例の $3.0 \%$ に相当した. anterior thalamoperforating artery, anterior choroidal artery, recurrent artery of Heubner $の$ 障害で各50\%と高頻度で, lateral, および medial striate artery 障害ではそれぞれ $25 \% ， 0 \%$ と少なかった (Table 5). 後遺症の内訳は, 対側の不全片麻痺 9 例, 見当識障害 2 例であった。

\section{考察}

近年，穿通枝の微小外科解剖に関する多数の報告が認め られ(1)7)9) 13), その重要性が強調されている. 脳動脈瘤手 
術においても，しばしばその温存が問題となる．今回のわ れわれの検討では 366 例中， 33 症例 $9.2 \%$ と思った以上に 高頻度の手術による穿通枝障害が認められ，これは動脈瘤 手術合併症のうちで, 最も多いものであった. 穿通枝障害 による後遺症は $39.3 \%$ で認められ，これは全動脈瘤手術 症例の $3.0 \%$ にすぎないが, 術中に, どの穿通枝の障害で どのような後遺症を呈するかの判断は不可能である。また 基本的に，動脈瘤手術に扔いては，いかなる血管も損傷す べきではなく, 穿通枝障害は極力避けなければならない. そこで今回その原因, 対策について検討した.

trans-sylvian approach ${ }^{6)}$ で clipping を行った anterior circulation の動脈瘤では, その確認が不十分となった穿通 枝の障害が 9 例と最も多く, 特に, anterior thalamoperforating artery, anterior choroidal artery の確認が問題とな ることが多かった．後交通動脈からは平均 7 8.5 本の穿 通枝が分岐し，その本数は後交通動脈の太さと関係せず,
Table 2A Injured perforating arteries in cases of IC, MC, and $\mathrm{A}_{1}$ aneurysms*

\begin{tabular}{lcccc}
\hline & A. Tha. P & A. ch & LSA & MSA \\
\hline IC & 7 & 7 & 1 & 4 \\
$P C$ & 6 & - & - & 1 \\
A. ch & - & 4 & - & - \\
$\quad$ terminal & - & 1 & - & - \\
$\quad \begin{array}{c}\text { duplicated } \\
\text { giant }\end{array}$ & - & - & 1 & - \\
MC & 1 & 2 & - & - \\
A $_{1}$ & - & - & 2 & - \\
\hline \multicolumn{1}{c}{ Total } & - & - & - & 2 \\
\hline
\end{tabular}

(*: All operations were performed via a trans-sylvian approach).

IC: internal carotid artery, MC: middle cerebral artery, $\mathrm{A}_{1}$ : anterior cerebral artery horizontal portion, PC: posterior communicating artery, A.ch.: anterior choroidal artery, A. Tha. P.: anterior thalamoperforating artery, LSA: lateral striate artery, MSA: medial striate artery.

Table 2B Relationship between the causes of perforator injury and the location of aneurysm

\begin{tabular}{|c|c|c|c|c|c|c|c|c|}
\hline & \multicolumn{5}{|c|}{ IC } & \multirow[b]{2}{*}{$\mathrm{MC}$} & \multirow[b]{2}{*}{$\mathrm{A}_{1}$} & \multirow[b]{2}{*}{ Tota } \\
\hline & $\mathrm{PC}$ & A.ch. & terminal & $\begin{array}{l}\text { duplicated } \\
\text { MC }\end{array}$ & giant & & & \\
\hline $\begin{array}{l}\text { insufficient identification } \\
\text { of perforator }\end{array}$ & 4 & 1 & 1 & - & 1 & 1 & 1 & 9 \\
\hline $\begin{array}{l}\text { temporary occlusion of } \\
\text { perforator or parent artery }\end{array}$ & 2 & 1 & - & - & - & 1 & - & 4 \\
\hline brain retraction & 1 & - & 2 & 1 & - & - & - & 4 \\
\hline kinking of perforator & - & 2 & 1 & - & - & - & 1 & 4 \\
\hline $\begin{array}{l}\text { perforators arise from } \\
\text { aneurysmal dome }\end{array}$ & - & - & - & - & 1 & - & - & 1 \\
\hline Total & 7 & 4 & 4 & 1 & 2 & 2 & 2 & \\
\hline
\end{tabular}

IC: internal carotid artery, MC: middle cerebral artery, $\mathrm{A}_{1}$ : anterior cerebral artery horizontal portion, A.ch.: anterior choroidal artery.

Table 3 Summary of the cases of Acom aneurysm with the perforator injury

\begin{tabular}{ccccc}
\hline & Age/Sex & Approach & Perforator & Cause \\
\hline 1 & $65 / \mathrm{M}$ & AIH & RAH & premature rupture \\
2 & $34 / \mathrm{M}$ & BIH & RAH & premature rupture \\
3 & $64 / \mathrm{F}$ & AIH & RAH & temporary clipping \\
4 & $57 / \mathrm{M}$ & BIH & bilateral RAH* & slipping of clip \\
5 & $55 / \mathrm{M}$ & AIH & unknown** & unknown \\
6 & $47 / \mathrm{F}$ & TS & RAH & kinking \\
\hline
\end{tabular}

M: male, F: female, AIH: anterior interhemispheric approach, $\mathrm{BIH}$ : basal interhemispheric approach, RAH: recurrent artery of Heubner, TS: trans-sylvian approach, *: bilateral $\mathrm{A}_{2}$ territory was also involved, **: infarction of the genu of corpus callosum.
Table 4 Summary of the cases of basilar aneurysm with perforator injury

\begin{tabular}{ccccc}
\hline & Age/Sex & $\begin{array}{c}\text { Site of } \\
\text { aneurysm }\end{array}$ & $\begin{array}{c}\text { Injured } \\
\text { perforator }\end{array}$ & Cause \\
\hline 1 & $57 / \mathrm{F}$ & BA-top & LSA & brain retraction \\
2 & $65 / \mathrm{F}$ & Ba-SCA & A.Tha.P. & retraction of IC \\
3 & $57 / \mathrm{F}$ & Ba-SCA & A.Tha.P. & retraction of IC \\
4 & $56 / \mathrm{F}$ & Ba-SCA & A.Tha.P. & retraction of IC \\
5 & $66 / \mathrm{F}$ & Ba-SCA & A.Tha.P. & retraction of IC \\
\hline
\end{tabular}

All operations were performed via a trans-sylvian approach. Case 1: between the optic nerve and the internal carotid artery. Case 2-5: lateral to the posterior communicating artery. M: male, F: female, IC: internal carotid artery, BA: basilar artery, A.Tha.P.: anterior thalamoperforating artery, LSA: lateral striate artery, SCA: superior cerebellar artery. 
Table 5 Cases with neurological deficit (3 months after operation)

\begin{tabular}{ccc}
\hline A.Tha.P & $4 / 8$ & $(50 \%)$ \\
A.ch. & $3 / 5$ & $(60 \%)$ \\
RAH & $2 / 4$ & $(50 \%)$ \\
LSA & $1 / 4$ & $(25 \%)$ \\
MSA & $0 / 6$ & $(0 \%)$ \\
unknown* & $1 / 1$ & $(100 \%)$ \\
\hline Total & $11 / 28$ & $(39.3 \%)$ \\
\hline
\end{tabular}

*: infarction of the genu of corpus callosum.

The neurological symptom was hemiparesis in 9 cases and disorientation in 2 cases.

A.Tha.P.: anterior thalamoperforating artery, A.ch.: anterior choroidal artery, RAH: recurrent artery of Heubner, LSA: lateral striate artery, MSA: medial striate artery.

また，前半部により多くの穿通枝が存在する．そのうち最 も存在頻度が高く，大きな穿通枝が， anterior thalamoperforating artery (premamillary artery, thalamotuberal artery) と呼ばれ, 内頸動脈から 2〜6 $\mathrm{mm}$ の部位より分 岐する ${ }^{10) 13)}$. anterior choroidal artery は通常 1 本，とき に数本存在し，その cisternal segment から, cerebral peduncle, temporal lobe, anterior perforating substance 等 へ枝を出している ${ }^{12)}$.こういった解剖学的知識を念頭に おくことはもちろんであるが, variationも多く，また， 術前の脳血管撮影からは穿通枝と動脈瘤の位置関係を完全 に把握することは困難であり, 術中の確認が重要である. しかし，母血管や動脈瘤，applyした clipの死角となりど うしても確認できない場合もあり，そういった症例では， 近年開発の進んでいる超細径内視鏡の応用が期待される. その他, 内頸動脈終末部や前大脳動脈水平部といった比較 的高位の動脈瘤では，過度の圧排が原因となることも多く 注意が必要である。また, anterior choroidal artery, striate arterial group といった細い穿通枝は, clipにより stenosis, kinking をきたしやすく, 配虑が必要である.

前交通動脈瘤に対しては，われわれは多発性動脈瘤の場 合を除き，原則的に interhemispheric approachを用いて いる ${ }^{17)}$. 本法で clipping を行う際に問題となる穿通枝に は， recurrent artery of Heubner および前交通動脈から分 岐する穿通枝がある。これらの穿通枝の走行，本数には variation も多く, Perlmutter らの 50 例の剖検脳の観察で は, recurrent artery of Heubner は, 78\%は $\mathrm{A}_{2}$ から, $14 \%$ は $\mathrm{A}_{1}$ から，8\%は前交通動脈の level から分岐してお り，欠損あるいは 2 本存在したのは，それぞれ一側ずつの みであったとしている。また，前交通動脈からは0〜4本
(平均 1.6 本)の穿通枝が分岐しており，その大部分は上面 あるいは後面から起始していた，と報告している11).し かし，三平ら，Nathalらの手術野での観察では，これら の穿通枝を確認しえなかった例も少なくなく，動脈瘤が両 側 $\mathrm{A}_{2}$ の間や後方に位置する場合にはその温存に注意が必 要である, としている8 ${ }^{14)}$. 今回の我々の検討では, premature rupture や temporary clipping による recurrent artery of Heubner の障害が多かった. interhemispheric approach は，脳に対する圧排が少なく，侵襲の少ない approach ではあるが, 術野が狭く深いため, より慎重な 手術操作, 手技の熟練が要求される.

posterior circulation の動脈瘤では, 脳底動脈分岐部 1 例, 脳底動脈一上小脳動脈分岐部 4 例で穿通枝障害が認め られた。脳底動脈分岐部動脈瘤の手術では, 動脈瘤周辺に 存在する穿通枝として, 後大脳動脈近位部 $\left(\mathrm{P}_{1}\right)$ および脳 底動脈の paramedian branch, とくに $\mathrm{P}_{1}$ から分岐する interpeduncular thalamoperforating artery の温存の重要性 が強調されている ${ }^{1) 7) 9)}$. 一方, 脳底動脈一上小脳動脈分岐 部動脈瘤はその周辺の穿通枝が問題となることは少ないと されている．しかし今回の検討では, 動脈瘤周辺に存在す る穿通枝の障害をきたした症例はなく，いずれも到達経路 途中にある穿通枝の障害であり, 脳や血管に対する retraction が原因と考えられた. とくに, 内頸動脈, 後交通 動脈を内側に圧排し, 後交通動脈の外側より approach し た症例で, anterior thalamoperforating artery の障害をき たした例が 4 例と多かった。この approach では，視神経 と内頸動脈の間，あるいは内頸動脈と後交通動脈の間から の approach に比し, 術野を防げる穿通枝が存在せず, 安 全な経路であり ${ }^{4)}$, 脳底動脈分岐部動脈瘤より低位に存在 することの多い脳底動脈一上小脳動脈分岐部動脈瘤ではこ の経路をとることが多い. しかし，その distal neck が高 位にある場合, 内頸動脈, 後交通動脈の圧排により,その 穿通枝に tension がかかり，その循環障害をきたす危険性 がある。近年, zygomatic approach ${ }^{3)}$, orbitozygomatic approach $^{5)}$, trans-cavernous approach ${ }^{2)}$ など, 種々の手術 法が開発されており，症例毎に脳への侵襲が少なく，広い 術野が得られる approach を選択することが重要である.

$$
\text { ま と め }
$$

1）脳動脈瘤手術により穿通枝障害をきたした 33 症例 $(9.2 \%)$ を検討した.

2）穿通枝障害の原因には，その不十分な確認， temporary clipping, premature rupture, kinking といった clipping 操作自体によるもののほか, 脳や血管の retractionによる循環障害も多かった.

3） $33 \%$ で神経脱落症状を遺し, anterior thalamoperforat- 
ing artery, anterior choroidal artery, recurrent artery of Heubner の障害で，その頻度が高かった。

4）対策として, 慎重な手術操作, 動脈瘤後面の十分な確 認, 最も侵襲の少ない approach の工夫が重要である.

\section{文献}

1) Caruso G, Vincentelli F, Giudicelli G, et al: Perforating branches of the basilar bifurcation. J Neurosurg 73: 259265, 1990

2) Dolenc V: Anatomy and Surgery of the Cavernous Sinus, Springer-Verlag, Wien-New York, 1989, pp 196-219

3) Fujitu K, Kuwabara T: Zygomatic approach for lesions in the interpeduncular cistern. J Neurosurg 62: 340-343, 1985

4) 宣保浩彦, 田中雄一郎, 小林茂昭, ほか: 脳底動脈瘤手術 における到達経路および穿通枝の外科解剖学的検討. 脳卒 中の外科 19: 343-347, 1991

5) Hakuba A, Liu S, Nishimura S: The orbitozygomatic infratemporal approach-A new surgical technique. Surg Neurol 26: $271-276,1986$

6）上山博康, 川村伸悟, 大田英則, ほか：中大脳動脈瘤, 内 頸動脈瘤に対する distal trans-Sylvian approach. 第 12 回脳 卒中の外科研究会講演集, にゅー万ん社, 東京, $1983, \mathrm{pp}$ 69-74

7) Marinkovic S, Milisavjevic M, Kovacevic M: Interpeduncular perforating branches of the posterior cerebral artery. Surg Neurol 26: 349-359, 1986

8) Nathal E, Yasui N, Sampei T, et al: Intraoperative anatomical studies in patients with aneurysms of the anterior communicating artery complex. J Neurosurg 76: 629-634, 1992

9) Pedroza A, Dujovny M, Ausman JI, et al: Microvascular anatomy of the interpeduncular fossa. J Neurosurg 64: 484-493, 1986

10) Pedroza A, Dujovny M, Artero JC, et al: Microanatomy of the posterior communicating artery. Neurosurgery 20: 228-235, 1987

11) Perlmutter D, Rhoton AL Jr: Microsurgical anatomy of the anterior cerebral-anterior communicating-recurrent artery complex. J Neurosurg 45: 259-272, 1976

12) Rhoton AL Jr, Fujii K, Fradd B: Microsurgical anatomy of the anterior choroidal artery. Surg Neurol 12: 171-187, 1979

13) Saeki N, Rhoton AL Jr: Microsurgical anatomy of the upper basilar artery and posterior circle of Willis. J Neurosurg 46: $563-578,1977$

14）三平剛志, 安井信之, 水野 誠, ほか: 前交通動脈瘤周囲 の血管構築について一Interhemispheric approach による術 中所見からの検討一. 脳卒中の外科 19: 59-64, 1991

15）安井信之, 鈴木明文, 波出石弘, ほか: 未破裂動脈瘤の治 療方針。第 50 回日本脳神経外科学会総会, 京都, 1991

16）安井信之：脳動脈瘤の治療, 現代医療社, 東京, 1990, pp 29-40

17）安井信之：一私の手術法一大脳半球間裂アプローチによる 前交通動脈瘤の手術法, にゅー万人社, 東京, 1991

18) Yasui $N$, Ito $Z$, Ohta $H$, et al: Surgical problems and pathophysiology in severcases with ruptured aneurysm in the acute stage. Acta Neurochir (Wien) 63: 163-174, 1982 